\title{
Spontaneous combustion risk in South African coalfields
}

\author{
by B. Genc* and A. Cook'
}

\section{Synopsis}

The risk of spontaneous combustion is well known in the South African coal mining industry. In the coming years it is very possible that the incidence of spontaneous combustion will increase from current levels, due to factors such as an increased rate of mining, re-working of previously mined seams, more stooping and total extraction for underground mines, and higher stripping ratios for surface mines, leading to more spoils. It is also fairly certain that coal mining will face tougher environmental emissions legislation in the near future. To determine the areas where the risks of spontaneous combustion are high, it is necessary to improve on our current laboratory procedures for testing and evaluating coal samples, combining the results with site and field data, and if necessary revising the laboratory rating system to refine our understanding of South African conditions.

Currently, laboratory tests are conducted in order to determine both the Wits-EHAC index and the crossing-point temperature which, when combined, give an indication of the spontaneous combustion propensities of the coal samples. This procedure has enabled the establishment of a database of results to review and evaluate South African coal seams. Using this database, the high-risk areas in terms of spontaneous combustion are identified. Tests have been undertaken for five consecutive years, between 2008 and 2012. In total, 119 coal samples from different coal seams and production coalfields have been analysed and classified through a series of laboratory tests. A comprehensive database of these results is available, and is continually being updated as new test results are added. This database will continue to expand, and to provide the basis for an improved risk evaluation methodology for spontaneous combustion.

\section{Keywords}

coal spontaneous combustion, risk assessment, Wits-EHAC liability index, crossing-point temperature. possible that the rate of spontaneous combustion will increase from its present low levels, due to factors such as higher ventilation pressures, an increased rate of mining, more working of previously mined seams, etc.

It is also fairly certain that coal mining will face tougher environmental legislation limiting emissions in the near future. To ascertain the areas where spontaneous combustion risks are high, it is necessary to improve current laboratory procedures for testing and evaluating coal samples, combine the result with site and field data, and if necessary revise the laboratory rating system to better reflect South African conditions.

The current laboratory tests are conducted in order to determine both the Wits-EHAC index and the crossing-point temperature, which are combined to obtain the propensities of the coal samples to undergo spontaneous combustion. This has resulted in a database of results to review and evaluate South African coal seams. Using this database, the high-risk areas in terms of spontaneous combustion can be identified. The tests, involving 119 samples, cover five consecutive years, between 2008 and 2012. The samples were from a wide variety of different coal seams and producing coalfields. All samples have been subjected to a series of laboratory tests, and the results analysed. A comprehensive database of these results is available, and is being continually updated as new test results are added.

\section{The spontaneous combustion test}

At the School of Mining Engineering at the University of the Witwatersrand (Wits), an

\footnotetext{
* University of the Witwatersrand, Johannesburg.

$\dagger$ Latona Consulting Pty. Ltd., Johannesburg.

(C) The Southern African Institute of Mining and Metallurgy, 2015. ISSN 2225-6253. This paper was first presented at the $21 \mathrm{st}$ Century challenges to the southern African coal sector, 4-5 March 2014, Emperors Palace, Hotel Casino Convention Resort, Johannesburg.
} 


\section{Spontaneous combustion risk in South African coalfields}

apparatus was developed nearly 30 years ago to measure the propensity of coal to undergo spontaneous combustion. This research was funded by the Government Mining Engineer's Explosion Hazard Advisory Committee (EHAC). The apparatus is used to test coals under predefined conditions, and a combustibility index (Wits-EHAC) is obtained. Although the propensity of coal to combust spontaneously can be determined using various laboratory techniques, ignition temperature tests are commonly used to study spontaneous combustion, as they yield rapid results. Ignition temperature tests use two methods:

> Crossing-point temperature (XPT)

- Differential thermal analysis (DTA)

to determine both the Wits-EHAC index and the XPT. The Wits-EHAC index is defined as: 1987)

Wits-EHAC index $=($ Stage II slope $/ X P T) \times 500($ Gouws,

When the temperature differential between a coal sample and an inert sample is plotted against the inert temperature, the portion of the graph where the coal is heating more rapidly than the inert sample, i.e. where an exothermic reaction is taking place, is referred to as Stage II.

According to Gouws (1987), the characteristics of the curves plotted using the obtained results (i.e. ignition temperature tests) are used to determine the propensity of coal for self-heating, and this is the basis for the Wits-EHAC liability index. It is important to understand that when an index value of coal is greater than five, there is a high propensity for spontaneous combustion, and when an index value is less than three, there is a low propensity for spontaneous combustion. An index value of between three and five indicates that the coal sample has a relatively medium risk of undergoing spontaneously combustion. As indicated in Table I, a higher index value represents a higher risk of a coal self-heating (Gouws, 1987).

The testing apparatus used for the Wits-EHAC index consists of an oil bath, six coal and inert material cell assemblies, an oil circulator, a heater, a flow meter used for air flow monitoring, an air supply compressor, and a computer. The temperatures are recorded every 20 seconds by

\begin{tabular}{|l|c|}
\hline \multicolumn{2}{|l|}{ Table I } \\
Spontaneous combustion liability index \\
\hline Index & Spontaneous combustion liability \\
\hline $0-3$ & Low \\
\hline $3-5$ & Medium \\
\hline$>5$ & High \\
\hline
\end{tabular}

\begin{tabular}{|c|c|c|c|c|c|c|}
\hline \multicolumn{7}{|c|}{$\begin{array}{l}\text { Table II } \\
\text { Spontaneous combustion test results between } \\
2008 \text { and } 2012\end{array}$} \\
\hline & 2008 & 2009 & 2010 & 2011 & 2012 & Total \\
\hline High & 7 & 13 & 20 & 6 & 6 & 52 \\
\hline Medium & 8 & 5 & 7 & 22 & 25 & 67 \\
\hline Total & 15 & 18 & 27 & 28 & 31 & 119 \\
\hline
\end{tabular}

the microcomputer during an average of 3-4 hours' testing time.

Detailed information regarding the testing apparatus used, as well as the testing procedure, is well documented by Genc et al. (2013).

\section{Results}

The tests were done over five consecutive years, between 2008 and 2012, with the spontaneous combustion liability index being obtained for all 119 samples. Table II shows the summary of the results. During this period there were no low-risk samples. Figure 1 represents graphically the total number of tests in terms of medium and high propensity.

Table III shows the results for spontaneous combustion tests in 2008 when 15 tests were conducted. The test results include the XPT in degrees Celsius $\left({ }^{\circ} \mathrm{C}\right)$ and the Wits-EHAC index. The names of the mines have been abbreviated. All of the coal samples tested produced results that ranged from medium to high propensity to spontaneous combustion, with an almost 50/50 split between medium (8) and high (7) propensity. The minimum calculated Wits-EHAC index was

Spontaneous Combustion Liability Total - 2008 to 2012

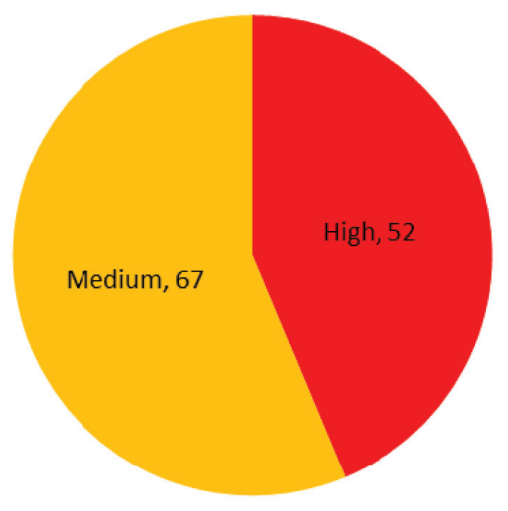

Figure 1 - Spontaneous combustion liability test results (2008-2012)

\begin{tabular}{|l|c|c|c|}
\hline \multicolumn{3}{|l|}{$\begin{array}{l}\text { Table III } \\
\text { Spontaneous combustion test results (2008) }\end{array}$} \\
\hline Mine & $\begin{array}{c}\text { Wits-EHAC } \\
\text { index }\end{array}$ & $\begin{array}{c}\text { Crossing-point } \\
\text { temperature } \\
\text { ('C) }\end{array}$ & $\begin{array}{c}\text { Spontaneous } \\
\text { combustion } \\
\text { liability }\end{array}$ \\
\hline $\mathrm{GB}$ & 4.87 & 127.4 & Medium \\
\hline $\mathrm{GB}$ & 5.03 & 125.1 & High \\
\hline $\mathrm{Um}$ & 5.22 & 119.3 & High \\
\hline $\mathrm{At}$ & 4.31 & 126.7 & Medium \\
\hline $\mathrm{MS}$ & 5.41 & 126.7 & High \\
\hline $\mathrm{MS}$ & 5.51 & 132.3 & High \\
\hline $\mathrm{MS}$ & 5.8 & 129.7 & High \\
\hline $\mathrm{KI}$ & 5.55 & 126.7 & High \\
\hline $\mathrm{Ma}$ & 5.15 & 124.9 & High \\
\hline $\mathrm{Ge}$ & 3.65 & 153.5 & Medium \\
\hline $\mathrm{Tw}$ & 4.09 & 133.6 & Medium \\
\hline $\mathrm{Ui}$ & 4.86 & 128 & Medium \\
\hline $\mathrm{Mb}$ & 4.96 & 131.6 & Medium \\
\hline $\mathrm{SS}$ & 4.55 & 130.9 & Medium \\
\hline $\mathrm{SL}$ & 4.9 & 110.4 & Medium \\
\hline
\end{tabular}




\section{Spontaneous combustion risk in South African coalfields}

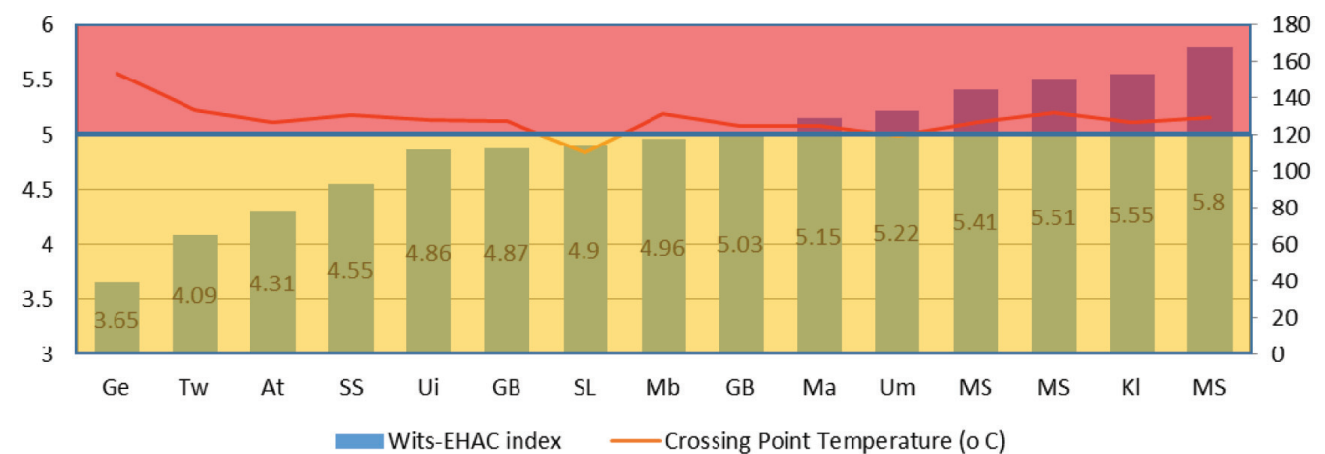

Figure 2 - Spontaneous combustion liability test results, 2008

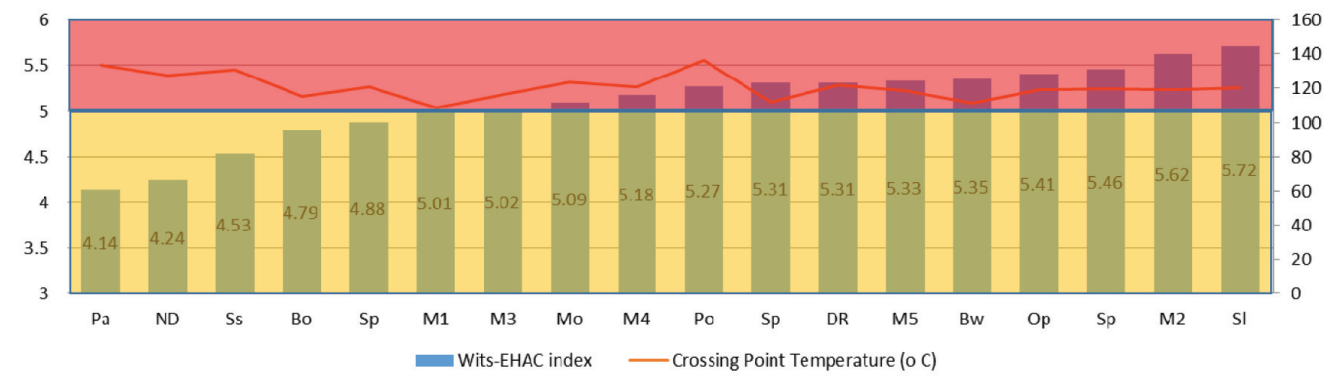

Figure 3 - Spontaneous combustion liability test results, 2009

3.65, and the maximum 5.8. Figure 2 shows the 2008 test results for spontaneous combustion liability. The Wits-EHAC index margins are indicated using colours. The yellow part shading indicates the coal samples that have a value of more than 3 but less than 5 , which are thought to possess a medium risk to spontaneous combustion. The red shading indicates samples that have a value of more than 5 and are, therefore, thought to have a high risk of spontaneous combustion.

Table IV shows the 2009 tests results for spontaneous combustion, when 18 tests were conducted. All of the tested coal samples showed medium to high propensity to spontaneously combust, and most of the collieries have high propensity (13 out of 18). The minimum calculated Wits-EHAC index was 4.14, and the maximum 5.72. Figure 3 shows the 2009 test results for spontaneous combustion liability.

Table V shows the 2010 tests results for spontaneous combustion, when 27 tests were conducted. The 2010 results show a very similar trend to the 2009 results, as most of the collieries tested had results in the high propensity range (20 out of 27). The minimum calculated Wits-EHAC index was 4.64 and the maximum 5.64. Figure 4 shows the 2010 test results for spontaneous combustion liability.

Table VI shows the 2011 tests results for spontaneous combustion, when 28 tests were conducted. Although the range was similar to that previously observed (i.e. medium to high), most of the collieries tested had results in the medium propensity range (22 out of 28). The reason for the difference in the test results from one year to the next is because every coal seam has different physical and chemical properties, and these impact on its propensity for spontaneous combustion. The minimum calculated Wits-EHAC index was 3.1, which is still just above the low range identified by Gouws (1987), while the maximum index was 5.91. Figure 5 shows the 2011 test results for spontaneous combustion liability.

Finally, Table VII shows the 2012 tests results of spontaneous combustion, when 31 tests were conducted. The 2012 results showed a very similar trend to 2011, as most of the collieries tested had a medium propensity ( 25 out of 31 ). The minimum calculated Wits-EHAC index was 3.71 and the maximum 5.75. Figure 6 shows the 2012 test results for spontaneous combustion liability.

\begin{tabular}{|c|c|c|c|}
\hline \multicolumn{4}{|c|}{$\begin{array}{l}\text { Table IV } \\
\text { Spontaneous combustion test results (2009) }\end{array}$} \\
\hline Mine & $\begin{array}{l}\text { Wits-EHAC } \\
\text { index }\end{array}$ & $\begin{array}{c}\text { Crossing-point } \\
\text { temperature } \\
\left({ }^{\circ} \mathrm{C}\right)\end{array}$ & $\begin{array}{c}\text { Spontaneous } \\
\text { combustion } \\
\text { liability }\end{array}$ \\
\hline ND & 4.24 & 127.6 & Medium \\
\hline $\mathrm{SI}$ & 5.72 & 120.2 & High \\
\hline Bo & 4.79 & 115.3 & Medium \\
\hline Mo & 5.09 & 123.3 & High \\
\hline M1 & 5.01 & 108.7 & High \\
\hline Po & 5.27 & 136.4 & High \\
\hline Op & 5.41 & 119.3 & High \\
\hline Sp & 5.31 & 111.9 & High \\
\hline $\mathrm{Sp}$ & 4.88 & 120.8 & Medium \\
\hline $\mathrm{Sp}$ & 5.46 & 119.9 & High \\
\hline Bw & 5.35 & 111.4 & High \\
\hline $\mathrm{Pa}$ & 4.14 & 133.4 & Medium \\
\hline DR & 5.31 & 121.9 & High \\
\hline Ss & 4.53 & 130.9 & Medium \\
\hline M2 & 5.62 & 119.2 & High \\
\hline M3 & 5.02 & 116.4 & High \\
\hline M4 & 5.18 & 121 & High \\
\hline M5 & 5.33 & 118.4 & High \\
\hline
\end{tabular}




\section{Spontaneous combustion risk in South African coalfields}

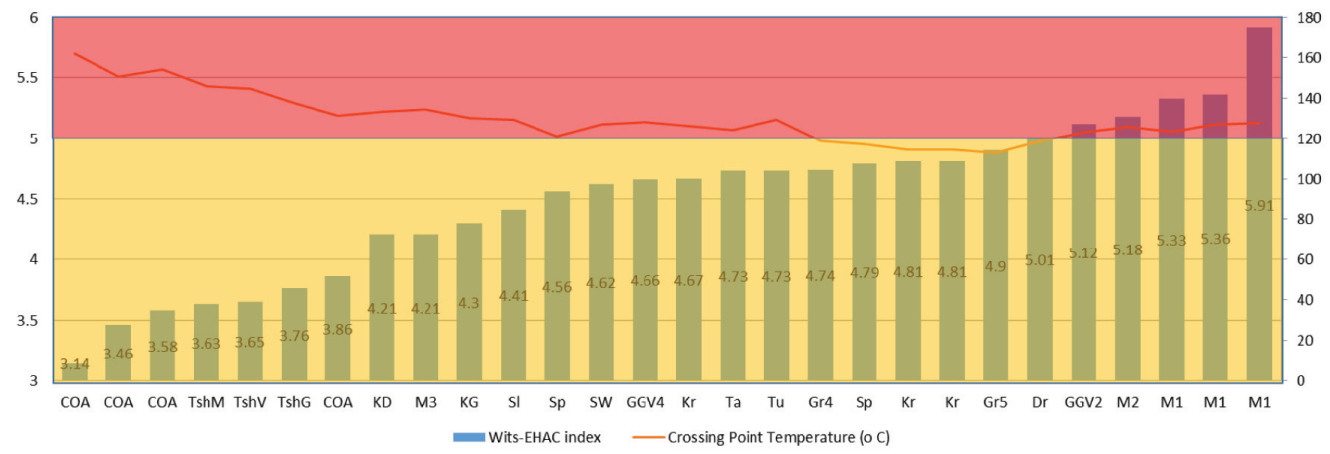

Figure 4 - Spontaneous combustion liability test results, 2010

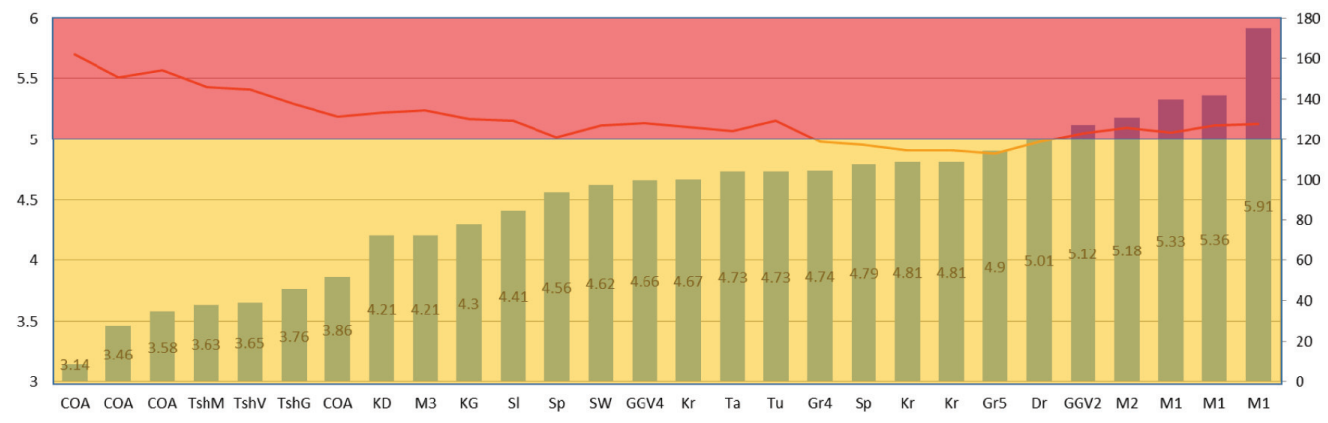

Wits-EHAC index C Crossing Point Temperature (o C)

Figure 5 - Spontaneous combustion liability test results, 2011

\begin{tabular}{|c|c|c|c|}
\hline \multicolumn{4}{|c|}{$\begin{array}{l}\text { Table V } \\
\text { Spontaneous combustion test results (2010) }\end{array}$} \\
\hline Mine & $\begin{array}{l}\text { Wits-EHAC } \\
\text { index }\end{array}$ & $\begin{array}{l}\text { Crossing-point } \\
\text { temperature } \\
\left({ }^{\circ} \mathrm{C}\right)\end{array}$ & $\begin{array}{l}\text { Spontaneous } \\
\text { combustion } \\
\text { liability }\end{array}$ \\
\hline Gr4 & 5.64 & 98.6 & High \\
\hline Gr5 & 5.44 & 102.6 & High \\
\hline Xs5 & 5.31 & 105.2 & High \\
\hline $\mathrm{Ma}$ & 5.14 & 109.3 & High \\
\hline $\mathrm{Ta}$ & 5.47 & 110.8 & High \\
\hline SW & 5.26 & 117.3 & High \\
\hline $\mathrm{SI}$ & 5.58 & 104.8 & High \\
\hline D16 & 4.91 & 118.8 & Medium \\
\hline D15 & 5.51 & 102.9 & High \\
\hline $\mathrm{Si}$ & 5.32 & 113.7 & High \\
\hline M1 & 4.64 & 117.8 & Medium \\
\hline $\mathrm{NC}$ & 5.02 & 119.3 & High \\
\hline $\mathrm{nK}$ & 5.38 & 108 & High \\
\hline Op & 5.49 & 108.2 & High \\
\hline Op & 5.23 & 120.9 & High \\
\hline Op & 5.1 & 110.8 & High \\
\hline Op & 5.52 & 113.6 & High \\
\hline Op & 5.27 & 117 & High \\
\hline Wy & 5.24 & 114.7 & High \\
\hline $\mathrm{DE}$ & 5.6 & 121.2 & High \\
\hline $\mathrm{VaA}$ & 5.58 & 95.2 & High \\
\hline $\mathrm{KE}$ & 4.86 & 120.2 & Medium \\
\hline KW & 4.71 & 113.9 & Medium \\
\hline Xs2 & 4.91 & 116.7 & Medium \\
\hline SW & 4.92 & 121.9 & Medium \\
\hline VaG & 4.86 & 108.5 & Medium \\
\hline Mo & 5.33 & 124.7 & High \\
\hline
\end{tabular}

\begin{tabular}{|c|c|c|c|}
\hline \multicolumn{4}{|c|}{$\begin{array}{l}\text { Table VI } \\
\text { Spontaneous combustion test results (2011) }\end{array}$} \\
\hline Mine & $\begin{array}{l}\text { Wits-EHAC } \\
\text { index }\end{array}$ & $\begin{array}{l}\text { Crossing-point } \\
\text { temperature } \\
\left({ }^{\circ} \mathrm{C}\right)\end{array}$ & $\begin{array}{l}\text { Spontaneous } \\
\text { combustion } \\
\text { liability }\end{array}$ \\
\hline $\mathrm{COA}$ & 3.14 & 161.9 & Medium \\
\hline $\mathrm{COA}$ & 3.46 & 150.5 & Medium \\
\hline $\mathrm{COA}$ & 3.58 & 154.3 & Medium \\
\hline TshM & 3.63 & 145.8 & Medium \\
\hline TshV & 3.65 & 144.8 & Medium \\
\hline TshG & 3.76 & 137.4 & Medium \\
\hline KD & 4.21 & 133.2 & Medium \\
\hline M3 & 4.21 & 134.6 & Medium \\
\hline KG & 4.3 & 130.3 & Medium \\
\hline SI & 4.41 & 129.4 & Medium \\
\hline $\mathrm{Sp}$ & 4.56 & 121.2 & medium \\
\hline SW & 4.62 & 126.9 & Medium \\
\hline GGV4 & 4.66 & 128.1 & Medium \\
\hline $\mathrm{Kr}$ & 4.67 & 126.2 & Medium \\
\hline $\mathrm{Ta}$ & 4.73 & 124.3 & Medium \\
\hline $\mathrm{Tu}$ & 4.73 & 129.3 & Medium \\
\hline Gr4 & 4.74 & 118.7 & Medium \\
\hline $\mathrm{Sp}$ & 4.79 & 117.3 & medium \\
\hline $\mathrm{Kr}$ & 4.81 & 114.2 & Medium \\
\hline $\mathrm{Kr}$ & 4.81 & 114.2 & Medium \\
\hline $\mathrm{COA}$ & 3.86 & 131.3 & Medium \\
\hline Gr5 & 4.9 & 112.9 & Medium \\
\hline $\mathrm{Dr}$ & 5.01 & 118.7 & High \\
\hline GGV2 & 5.12 & 123.2 & High \\
\hline M2 & 5.18 & 125.9 & High \\
\hline M1 & 5.33 & 123.4 & High \\
\hline M1 & 5.36 & 126.8 & High \\
\hline M1 & 5.91 & 127.8 & High \\
\hline
\end{tabular}




\section{Spontaneous combustion risk in South African coalfields}

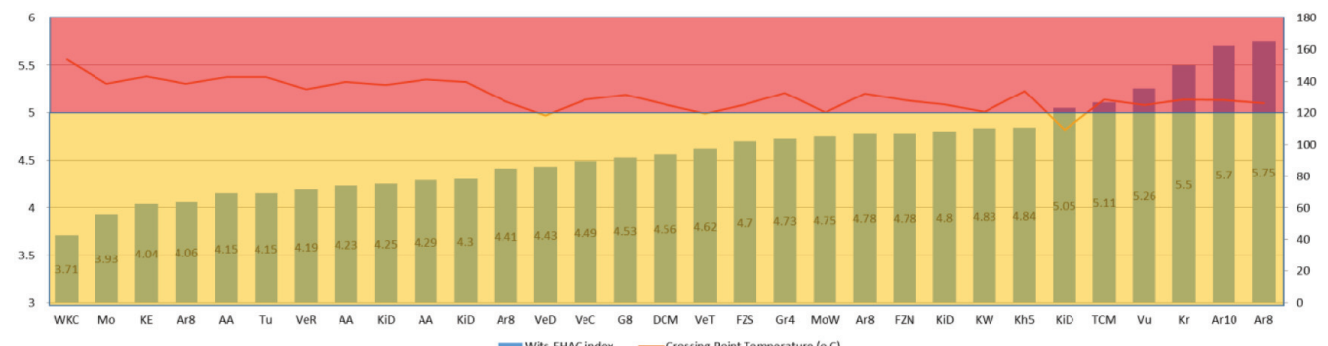

Figure 6 - Spontaneous combustion liability test results, 2012

\section{Analysis}

To address spontaneous combustion problems in South African collieries, 119 tests were conducted over five consecutive years and the results were rated according to the Wits-EHAC index. The analysis shows that none of the samples fell in the low-risk category. Sixty-seven out of 119 tested collieries possess a medium risk of spontaneous combustion (almost 56.3 per cent), while the remaining collieries (43.7 per cent) possess a high risk of spontaneous combustion (about a 13 per cent difference). Figure 7 shows the propensity for spontaneous combustion percentages for all 119 tests.

\begin{tabular}{|c|c|c|c|}
\hline \multicolumn{4}{|c|}{$\begin{array}{l}\text { Table VII } \\
\text { Spontaneous combustion test results (2012) }\end{array}$} \\
\hline Mine & $\begin{array}{l}\text { Wits-EHAC } \\
\text { index }\end{array}$ & $\begin{array}{l}\text { Crossing-point } \\
\text { temperature } \\
\left({ }^{\circ} \mathrm{C}\right)\end{array}$ & $\begin{array}{l}\text { Spontaneous } \\
\text { combustion } \\
\text { liability }\end{array}$ \\
\hline$A A$ & 4.23 & 139.6 & Medium \\
\hline$A A$ & 4.29 & 141 & Medium \\
\hline AA & 4.15 & 142.9 & Medium \\
\hline G8 & 4.53 & 131.4 & Medium \\
\hline Gr4 & 4.73 & 132.5 & Medium \\
\hline $\mathrm{Kr}$ & 5.5 & 128.2 & High \\
\hline Kh5 & 4.84 & 133.7 & Medium \\
\hline Ar8 & 4.78 & 132.1 & Medium \\
\hline Ar8 & 4.41 & 127.2 & Medium \\
\hline Ar8 & 4.06 & 138.3 & Medium \\
\hline Ar8 & 5.75 & 126 & High \\
\hline Ar10 & 5.7 & 127.9 & High \\
\hline KiD & 5.05 & 109 & High \\
\hline KiD & 4.25 & 137.8 & Medium \\
\hline KiD & 4.8 & 125.1 & Medium \\
\hline KiD & 4.3 & 139.6 & Medium \\
\hline VeD & 4.43 & 117.9 & Medium \\
\hline $\mathrm{VeC}$ & 4.49 & 128.2 & Medium \\
\hline $\mathrm{VeT}$ & 4.62 & 119.3 & Medium \\
\hline VeR & 4.19 & 134.8 & Medium \\
\hline MoW & 4.75 & 119.9 & Medium \\
\hline $\mathrm{Vu}$ & 5.26 & 124.8 & High \\
\hline Mo & 3.93 & 138.3 & Medium \\
\hline TCM & 5.11 & 128.1 & High \\
\hline DCM & 4.56 & 125.1 & Medium \\
\hline FZN & 4.78 & 127.8 & Medium \\
\hline FZS & 4.7 & 124.9 & Medium \\
\hline WKC & 3.71 & 153.8 & Medium \\
\hline $\mathrm{KE}$ & 4.04 & 143.3 & Medium \\
\hline $\mathrm{KW}$ & 4.83 & 120.4 & Medium \\
\hline Tu & 4.15 & 142.9 & Medium \\
\hline
\end{tabular}

Spontaneous Combustion Liability Total - 2008 to 2012

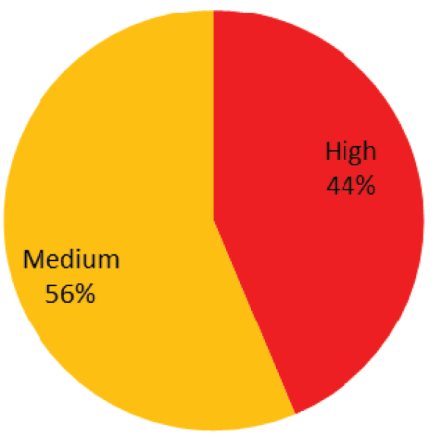

Figure 7 - Spontaneous combustion liability test results in percentage, 2008-2012

The results indicate that spontaneous combustion propensity is dependent on the properties of each coal seam. In 2010, when the largest high-risk rating percentage was recorded, test results showed that more than 74 per cent of the mines were in this high-risk category, compared with about 21 per cent in 2011 and 19 per cent in 2012. In 2009, similar to 2010, 72 per cent of the mines had high risk ratings. In 2008 , the high and medium rating percentages were very close; 47 and 53 per cent, respectively.

The results show that, given the right environmental conditions, most of the collieries located in the Witbank and Highveld coalfields have a high risk of spontaneous combustion. The high-risk areas also include the northeastern part of Ogies. The southern parts of Witbank coalfield, in the Ermelo area, are also rated high in terms of risk. Although 52 out of 119 collieries have a high inherent risk of spontaneous combustion, most of the selected collieries possess medium risk ratings. Medium risk ratings can be seen around the northern parts of Ermelo, as well as in KwaZulu-Natal Province where anthracite coal is mined.

It is interesting that there were no low-range results recorded during the five-year testing period from 2008 to 2012. This finding indicates that there is a need to re-visit the current definition of the spontaneous combustion liability index within the ranges of low, medium, or high; but this requires a further study as to how Gouws (1987) defined these ranges and, if it is necessary to change the current definitions, at what levels should the new criteria should be set. 


\section{Spontaneous combustion risk in South African coalfields}

\section{Conclusion}

The inherent propensity for spontaneous combustion to occur at the selected South African collieries was analysed and classified through a series of laboratory tests. It is evident that, despite the low frequency of underground incidents, South African collieries do have the risk of spontaneous combustion. In all, 119 tests were conducted between 2008 and 2012. The test results indicated that the majority of South African collieries have medium risk ratings ( 56.3 per cent), and the propensity of spontaneous combustion of the collieries ranges from medium to high.

There results and the subsequent analysis highlight a significant concern - that there are no low-range results , and this emphasizes the importance of monitoring the early signs of spontaneous combustion in the collieries. However, there is also the need to re-visit the definitions of low, medium, and high risk for the spontaneous combustion liability index, and this will require further research. There is already a considerable body of evidence that the seams of the Waterberg coalfield are particularly prone to spontaneous combustion, and there will be a definite need to incorporate those results into any new research.
Based on the tests results, it was found that there are high spontaneous combustion risks in the Witbank and Highveld coalfields. Relatively low spontaneous combustion risk was found in the KwaZulu-Natal coalfield, where anthracite coal is mined, as well as the northern parts of Ermelo coalfield.

\section{References}

GeNc, B. and Соок, A. 2013. Determination of spontaneous combustion risk in the South African coalfields. 23rd International Mining Congress and Fair, Antalya, Turkey, 16-19 April 2013.

Gouws, M.J. 1987. Crossing point characteristics and differential thermal analysis of South African coals. MSc dissertation, University of the Witwatersrand, Johannesburg.

Phillips, H., Chabedi, K., and Uludag, S. 2011. Best Practice Guidelines for South African Collieries.

http://www.coaltech.co.za/Annual_Colloquium/Colloquim\%202011/Spont aneous\%20Combustion\%20Prevention $\% 20$ and\%20Control\%20by\%20Hu w\%20Phillips,\%20Kelello\%20Chabedi\%20\&\%20Sezer\%20Uludag.pdf [Accessed 5 January 2014]. 